\title{
Peripheral blood lymphocyte subset levels differ in patients with hepatocellular carcinoma
}

\author{
Hai-Zhou Liu ${ }^{1}$, Wei Deng ${ }^{1}$, Ji-Lin Li $^{1}$, Ya-Mei Tang ${ }^{1}$, Li-Tu Zhang ${ }^{1}$, Ying Cui ${ }^{1}$, \\ Xin-Qiang Liang ${ }^{1}$ \\ ${ }^{1}$ Department of Medical Research, The Affiliated Tumor Hospital of Guangxi Medical University, 530021 Nanning, Guangxi, \\ P.R. China
}

Correspondence to: Xin-Qiang Liang, email: Liang_XinQiang23@163.com

Keywords: hepatocellular carcinoma, $C D 3^{+}, C D 4^{+}, C D 19^{+}, \mathrm{NK}$ cells

Received: April 02, 2016

Accepted: September 13, 2016

Published: November 03, 2016

\section{ABSTRACT}

We investigated the levels of target lymphocyte subsets in peripheral blood Iymphocyte samples from patients with hepatocellular carcinoma (HCC). A total of 715 high-risk patients with primary HCC were recruited in Guangxi, China as the case group. The control group included 100 patients who received health examinations at the same hospital during the same period. Fasting elbow venous blood $(10 \mathrm{~mL})$ was collected from each participant, and flow cytometry was used to detect the levels of NK cells and $\mathrm{CD}^{+}, \mathrm{CD}^{+}$and $\mathrm{CD}^{+}{ }^{+} \mathrm{T}$ cells in peripheral blood samples. All included patients with prmary HCC were treated by surgical resection, and followed up for one year. The levels of $\mathrm{CD}^{19}{ }^{+}$and $\mathrm{NK}$ cells were lower in cases than in controls (both $P<0.05)$. In addition, the level of $\mathrm{CDB}^{+}$cells was greater in the case group than in the control group $(P<0.05)$. In the high-HCC-risk population, $\mathrm{CDB}^{+}, \mathrm{CD}^{2} \mathrm{9}^{+}$and $\mathrm{NK}$ cell levels all differed between male and female patients, patients in TNM stages I-II and stages III-IV, patients with and without extrahepatic metastasis, and patients with and without $\mathrm{HBV}$ infection (all $P<0.05$ ). After follow-up, detected recurrence and survival rate was $33.71 \%$ and $83.64 \%$, respectively. CD8 $^{+}$levels was reduced following surgical resection, whereas the levels of $\mathrm{CD}^{19^{+}}$and NK cells were increased (all $P<0.05$ ). In conclusion, altered levels of $\mathrm{CDB}^{+}, \mathrm{CD} 19^{+}$and $\mathrm{NK}$ cell levels may be used as reference values for monitoring immune function in certain populations with high HCC risk, and as potential evidence for the clinical diagnosis and treatment of HCC.

\section{INTRODUCTION}

Hepatocellular carcinoma (HCC), usually secondary to either cirrhosis or viral hepatitis infection, is documented to be the fifth most common cancer in males (523,000 cases per year), the seventh most common cancer in females $(226,000$ cases per year) worldwide [1], and the third most common cause of cancer-related mortality globally [2]. The incidence rate of HCC varies substantially across different geographic regions, but the majority of the HCC burden is in developing countries, in which up to $85 \%$ of all cases take place [3]. Furthermore, over $75 \%$ of HCC cases occur in the Asia-Pacific region, and about half of HCC cases and deaths are estimated to occur in China $[4,5]$. In China, there is a high-risk population for HCC, especially in the southeast coastal area of our country. Due to its asymptomatic features, $\mathrm{HCC}$ is often diagnosed at a late stage, at which point the disease is characterized by large tumors, unresectable lesions, a high metastasis rate, and a five-year survival rate below $5 \%[6,7]$. The etiology of HCC probably involves interactions among multiple risk factors, including nonspecific cirrhosis induced by chronic hepatitis $\mathrm{B}$ virus (HBV) or hepatitis $\mathrm{C}$ virus (HCV) infection, alcohol intoxication, exposure to aflatoxins, metabolic disorders, and immune-related dysfunction [8].

In the immune response to cancer, cellular and humoral immunity work together to kill tumor cells [9], but the former is more important than the latter. Lymphocytes are one of the most important cell groups in the immune system, and are divided into three categories based on the expression and biological function of their 
cell surface differentiation antigens: T lymphocytes (which are involved in cellular immunity), B lymphocytes (which are involved in humoral immunity) and natural killer (NK) cells (which directly kill tumor cells and virus-infected cells) [10-12]. Human tumor progression correlates significantly with immunologic function [13, 14]; for example, HBV infection disrupts the balance of the lymphocyte subsets and thereby changes their proportions in the peripheral blood, reflecting the immune state of body to a certain extent $[15,16]$.

$\mathrm{T}$ cells can be divided into cytotoxic $\mathrm{T}$ lymphocytes (CTL), helper $\mathrm{T}$ lymphocytes (TH) and suppressor $\mathrm{T}$ lymphocytes (TS) according to their functions and main surface markers (CD8 CD4, and CD19, respectively) [17]. $\mathrm{CD}^{+}$cells are also known as killer T cells; $\mathrm{CD}^{+}$cells can proliferate to activate other types of immune cells that produce direct immune responses or provide auxiliary help to other lymphocytes; and $\mathrm{CD}^{1} 9^{+}$cells inhibit helper $\mathrm{T}$ cell activity, thus indirectly inhibiting $\mathrm{B}$ cell differentiation and the TC killing function and negatively regulating the humoral and cellular immune responses of the T cell subsets $[18,19]$. B cells participate in specific humoral immune responses; for instance, CD19+ $\mathrm{B}$ cells can only be activated and differentiate into mature plasma cells when there are TH cells and interleukin-1 regulated factors, to generate antigen-specific immunoglobulin and to have effect onhumoral immunity [20]. Natural killer (NK) cells depend on antigen stimulation, and can directly kill a variety of tumor cells and virus-infected cells (for instance, by activating phagocytic cells) [21].

In the present study, we detected the levels of the lymphocyte subsets in peripheral blood lymphocyte samples from HCC patients in China, in order to understand the immune status of these patients, and to obtain evidence about the changes in the proportions of these subsets for application in the clinical diagnosis and treatment of HCC.

\section{RESULTS}

\section{General information and comparison of biochemical parameters}

Basic information about the study subjects and the results of biochemical measurements for the study groups are shown in Table 1 . In the case group $(n=715)$, there were 535 males and 180 females, with a mean age of $50.3 \pm 10.3$ years. In the control group, there were 83 males and 17 females, with an average age of $49.6 \pm$ 10.5 years. There was no significant difference in gender or age between the groups (both $P<0.05$ ). The body mass index (BMI) level was significantly greater in the case group than in the control group $(P<0.05)$. With regard to the tumor numbers in the HCC case group, 306 patients had a single tumor, while the remaining 409 patients had multiple tumors.

\section{Comparison of lymphocyte subset levels between groups}

As shown in Table 2, the levels of NK cells and $\mathrm{CD}^{+}, \mathrm{CD}^{+}, \mathrm{CD} 19^{+} \mathrm{T}$ cells in peripheral blood samples all tended to be lower in the case group than in the control group; however, only the $\mathrm{CD} 19^{+}$and $\mathrm{NK}$ cell levels differed significantly between the groups (both $P<0.05)$. On the other hand, the level of $\mathrm{CD}^{+}$cells was clearly greater in the case group than in the control group $(P<0.05)$.

\section{Comparison of lymphocyte subset levels within the case group}

The comparisons of $\mathrm{CD}^{+}, \mathrm{CD} 19^{+}$and $\mathrm{NK}$ cell levels in patients with different clinical parameters within the case group are shown in Table 3 . Within the high$\mathrm{HCC}$-risk population, significant differences in $\mathrm{CD}^{+}$, $\mathrm{CD}_{19}{ }^{+}$and NK cell levels were found between male and female patients, patients in TNM stages I-II and stages IIIIV, patients with and without extrahepatic metastasis, and patients with and without HBV infection (all $P<0.05$ ). However, the $\mathrm{CD}^{+}, \mathrm{CD} 19^{+}$and $\mathrm{NK}$ cell levels did not differ significantly according to the tumor number or Child-Pugh distribution in this population (all $P>0.05$ ).

\section{Survival analysis}

Until January 2015, 38 cases of HCC patients were lost during the follow-up period, with a loss ratio of follow-up of $5.31 \%$. The patients underwent surgical treatment, and the surgical treatment was good. There were no death and no complications (such as hepatic failure, hemorrhoea or abdominal infection) during treatment. Eligible patients were followed up for one year, 241 patients experienced tumor recurrence, and corresponding recurrence rate was $33.71 \%$. Furthermore, after follow-up, there were 598 cases of patients survived from surgical treatment, with a survival rate of $83.64 \%$. Accordingly, $\mathrm{CD}^{+}$levels was estimated to be reduced following surgical resection $(29.3 \pm 11.6$ vs. $22.4 \pm 8.9)$, whereas the levels of $\mathrm{CD}^{+} 9^{+}(3.0 \pm 2.7$ vs. $11.4 \pm 3.8)$ and NK cells $(15.1 \pm 8.3$ vs. $17.8 \pm 6.4)$ were on the other hand increased significantly, showing statistical difference (all $P<0.05$ ).

\section{DISCUSSION}

It is widely accepted that malignant tumors are caused by reduced immune function $[13,22]$. Furthermore, there is ample evidence that the occurrence and development of HCC is associated with the status of the adaptive immune system, and that a normally functioning system can potentially induce therapeutic antitumor immunity [23, 24]. Lymphocytes (T lymphocytes, B 
Table 1: General information and biochemical parameters comparison among the three different groups

\begin{tabular}{lccc}
\hline & Case group $(\boldsymbol{n}=\mathbf{7 1 5})$ & Control group $(\boldsymbol{n}=\mathbf{1 0 0})$ & $\boldsymbol{P}$ value \\
\hline Age (years) & $50.3 \pm 10.3$ & $49.6 \pm 10.5$ & 0.526 \\
Genders (M/F) & $535 / 180$ & $63 / 37$ & 0.070 \\
BMI & $28.8 \pm 5.1^{*}$ & $22.1 \pm 4.4$ & $<0.001$ \\
Tumor sizes & $5.5 \pm 4.2$ & $/$ & $/$ \\
Tumor numbers (Singly/Multiply) & $306 / 409$ & $/$ & $/$ \\
TNM stages (I/II/III/IV) & $98 / 290 / 192 / 135$ & $/$ & $/$ \\
Child-Pugh (A/B/C) & $458 / 139 / 118$ & $/$ & $/$ \\
Extrahepatic metastasis & $139 / 576$ & 19 & $<0.001$ \\
HBV infection & 574 & 0 & $<0.001$ \\
HCV infection & 141 & $/$ & $/$ \\
\hline
\end{tabular}

Note: ", compared with the control group, $P<0.05$. M, male; F, female; BMI, body mass index; HBV, hepatitis B virus; HCV, hepatitis $\mathrm{C}$ virus.

Table 2: The comparison of levels of lymphocyte subsets and NK cells between the case group and the control group

\begin{tabular}{lcccccc}
\hline & $\boldsymbol{n}$ & CD8 $^{+}$ & CD19 $^{+}$ & CD3 $^{+}$ & CD4 $^{+}$ & NK $^{*}$ \\
\hline Case group & 715 & $29.3 \pm 11.6^{*}$ & $3.0 \pm 2.7^{*}$ & $69.3 \pm 11.9$ & $35.1 \pm 10.2$ & $15.1 \pm 8.3^{*}$ \\
Control group & 100 & $24.7 \pm 6.1$ & $13.6 \pm 3.9$ & $69.6 \pm 10.5$ & $35.7 \pm 7.3$ & $17.0 \pm 5.2$ \\
$P$ value & & $<0.001$ & $<0.001$ & 0.798 & 0.578 & 0.026 \\
\hline
\end{tabular}

Note: *, compared with the control group, $P<0.05$. NK, natural killer.

lymphocytes and NK cells) are the most important cell group involved in maintaining immunological balance by suppressing a large number of immune responses [25-28]. Abnormal proportions of these subsets and their associated functions may disrupt the balance of the immune system [29]. In view of the important activities of these cells, we detected the levels of the different lymphocyte subsets in peripheral blood lymphocyte samples from patients with HCC.

We found that the levels of $\mathrm{CD}^{+}, \mathrm{CD}^{+}, \mathrm{CD} 19^{+} \mathrm{T}$ cells and NK cells in peripheral blood samples all tended to be reduced in high-risk HCC patients (the case group), whereas the level of $\mathrm{CD}^{+}$cells was greater in the case group than in the control group, suggesting that HBV infection alters the proportions of the peripheral blood lymphocyte subsets. A large number of studies have confirmed that $\mathrm{T}$ cells are one of the most important antiviral cell populations [30-32]. During both HBV and $\mathrm{HCV}$ infections, specific $\mathrm{T}$ cells are functionally depleted as they clear the infection [33]. Therefore, the reduced number of $\mathrm{CD}^{+}, \mathrm{CD}^{+}, \mathrm{CD} 19^{+} \mathrm{T}$ cells in patients with $\mathrm{HCC}$ to some extent indicates a decline in the body's antiviral ability, which ultimately contributes to the deterioration of diseases caused by persistent virus infection.
Furthermore, NK cells exert antiviral, antifibrotic and antitumor functions [18, 34, 35], and the reduced proportion of NK cells in patients with different stages of HBV infection suggests that NK cells may be involved in the progression of HCC. Previous work has shown that NK cells can kill hepatic stellate cells (HSCs), which are considered to be critical for the development of liver fibrosis [36]. High expression of HSCs activates $\alpha$-smooth muscle actin, which induces the secretion of a large amount of collagen and ultimately leads to fibrosis and cirrhosis of the liver [37]. A variety of immune cells, cytokines, and chemokines in the host immune system have been suggested to stimulate the activation of HSCs in the development of hepatic fibrosis [38-40]. NK cells can suppress activated HSCs to inhibit hepatic fibrosis and further canceration, the mechanism of which may involve several molecular pathways (e.g., TRAIL, FAS/FASL and NKG2D) and requires further confirmation[41-43]. Consistent with these observations, NK cells tended to be reduced in high-risk HCC patients in this study, so the levels of these cells may be meaningful for predicting HCC progression.

Further investigation revealed that the proportions of the target lymphocyte subsets also differed significantly between male and female patients, patients in TNM 


\begin{tabular}{|c|c|c|c|}
\hline & $\mathrm{CD8}^{+}$ & $\mathrm{CD}^{+}{ }^{+}$ & NK \\
\hline \multicolumn{4}{|l|}{ Genders } \\
\hline Male & $30.1 \pm 10.2^{*}$ & $3.0 \pm 2.6^{*}$ & $16.1 \pm 8.4^{*}$ \\
\hline Female & $25.9 \pm 9.7$ & $3.3 \pm 2.4$ & $13.6 \pm 8.0$ \\
\hline \multicolumn{4}{|l|}{ Tumor numbers } \\
\hline Singly & $28.9 \pm 10.1$ & $3.0 \pm 2.6$ & $15.6 \pm 8.3$ \\
\hline Multiply & $29.2 \pm 10.2$ & $3.0 \pm 2.6$ & $15.8 \pm 8.3$ \\
\hline \multicolumn{4}{|l|}{ TNM stages } \\
\hline I-II & $25.6 \pm 9.8$ & $3.3 \pm 2.4$ & $13.5 \pm 8.0$ \\
\hline III-IV & $30.1 \pm 10.1^{*}$ & $2.9 \pm 2.7^{*}$ & $16.3 \pm 8.3^{*}$ \\
\hline \multicolumn{4}{|l|}{ Child-Pugh } \\
\hline A & $27.5 \pm 9.7$ & $3.1 \pm 2.5$ & $14.8 \pm 7.8$ \\
\hline $\mathrm{B}$ & $28.7 \pm 10.0$ & $3.0 \pm 2.6$ & $14.3 \pm 8.0$ \\
\hline $\mathrm{C}$ & $29.0 \pm 10.0$ & $3.1 \pm 2.6$ & $15.6 \pm 8.1$ \\
\hline \multicolumn{4}{|c|}{ Extrahepatic metastasis } \\
\hline With & $30.1 \pm 9.7^{*}$ & $3.1 \pm 2.6^{*}$ & $15.9 \pm 8.2^{*}$ \\
\hline Without & $25.5 \pm 9.4$ & $3.3 \pm 2.7$ & $11.8 \pm 7.7$ \\
\hline \multicolumn{4}{|l|}{ Infection } \\
\hline HBV infection & $29.3 \pm 10.2^{*}$ & $3.0 \pm 2.6^{*}$ & $16.0 \pm 8.4^{*}$ \\
\hline HCV infection & $26.1 \pm 9.5$ & $3.3 \pm 2.9$ & $12.3 \pm 8.0$ \\
\hline
\end{tabular}

Note: *, compared between groups, $P<0.05$. Hepatitis $\mathrm{B}$ virus; $\mathrm{HCV}$, hepatitis $\mathrm{C}$ virus.

stages I-II and stages III-IV, patients with and without extrahepatic metastasis, and patients with and without HBV infection within the high-HCC-risk population. However, the proportions of these subsets did not differ significantly according to the tumor number or Child-Pugh distribution, which may be attributed to the functions of the $\mathrm{CD}^{+}, \mathrm{CD} 19^{+}$and NK cell levels in the high-HCCrisk population, and differences in the lifestyles, dietary patterns, health and economic conditions of the patients. The different lifestyles, dietary patterns, and health conditions between men and women may be critical determinants of the development of HCC. In addition, patients with aggressive clinicopathological features are obviously prone to serious disease progression; accordingly, TNM stage, metastasis, and HBV infection strongly correlated with the severity and extent of malignancy.

Meanwhile, as for the results of survival analysis after surgical treatment, corresponding recurrence rates was still relatively higher and the survival rates should be improved, level of $\mathrm{CD} 8^{+}$cells was reduced whereas $\mathrm{CD} 19^{+}$ and NK cells leves were increased. Notably, the immune function of the body has a very complex regulatory mechanism, especially of the cellular immunity, all kinds of cell subsets and their products interact and regulate each other to maintain the normal immune response capability. Above mentioned lymphocyte levels changed significantly before and after treatment, suggesting that suitable therapies should be adopted to restore the immune state of the body as soon as possible, which will in turn contribute a lot to the reduction of complications and to promote postoperative recovery of disease courses, and thereby is beneficial for inhibiting in vivo rapid growth of metastasis caused by further decline in immune function.

To summarize, altered $\mathrm{CD} 8^{+}, \mathrm{CD} 19^{+}$and $\mathrm{NK}$ cell levels may be used as reference values for monitoring the immune function of certain populations with high HCC risk, and as evidence for the clinical diagnosis and treatment of HCC. However, there were some limitations to this study. For instance, $\mathrm{CD}$ values are known to differ according to ethnicity, but only an area demonstrating high HCC risk in China was investigated in this study. Also, there are limited data regarding the association of $\mathrm{CD}$ values and NK cell levels with prognostic outcomes of HCC. Considering the above limitations, further studies should be conducted with larger sample sizes to validate the findings we have presented, analyze specific subgroups (such as patients after surgical intervention), 
and correlate these findings with post-surgery outcomes after long-term follow-up.

\section{MATERIALS AND METHODS}

\section{Study objects}

In total, 715 patients with high-risk primary HCC were recruited in Guangxi, China as the case group for the present study. These patients had been admitted to The Affiliated Tumor Hospital of Guangxi Medical University for surgical treatment from January 2012 to January 2014, and included 535 males and 180 females ranging from 26 to 78 years in age. All patients were scanned by means of magnetic resonance imaging, abdominal B ultrasound and computed tomography, and were examined for clinical symptoms and signs, with alpha fetoprotein levels of 17-3000 ng/mL. The inclusion criteria were: (1) confirmation of primary HCC by clinical manifestation and histopathological examination of liver biopsy specimens associated with imaging diagnosis; (2) diagnosis of HBV infection following serologic tests (HBsAg positive); (3) poor liver function or a tumor with a maximum diameter greater than $5 \mathrm{~cm}$; and (4) no previous chemotherapy or radiation therapy. The exclusion criteria were: (1) severe dysfunction of the heart, liver or kidney; (2) combined immune and endocrine system diseases; (3) history of malignant tumors in other organs and liver metastasis; (4) antiviral drug treatment prior to admission; (5) concurrent $\mathrm{HCV}$, hepatitis A, hepatitis $\mathrm{E}$, or human immunodeficiency virus infection; and (6) other types of liver disease, such as autoimmune liver disease, inherited metabolic liver disease, alcoholic liver disease, schistosomiasis-related liver disease, liver disease of unknown cause, etc. The control group included 100 patients from The Affiliated Tumor Hospital of Guangxi Medical University who had received health examinations during the same period, among whom 63 were male, 37 were female, and the average age was $49.6 \pm 10.5$ years. The included controls were all negative for hepatitis B surface antigen/antibody, hepatitis B e antigen/e antibody, and hepatitis B core antibody, and had normal levels of alanine aminotransferase (ALT) and glutamic oxaloacetic transaminase (AST). This study was approved by the Ethics Committee of The Affiliated Tumor Hospital of Guangxi Medical University, and all the included subjects were informed of the study procedures and signed informed consent forms.

\section{Blood sample collection}

Fasting elbow venous blood $(10 \mathrm{~mL})$ was collected from each participant in the morning, of which $5 \mathrm{~mL}$ was collected without an anticoagulant. These 5-mL samples were placed in a water bath at $37^{\circ} \mathrm{C}$ for $30 \mathrm{~min}$ and centrifuged at $1400 \times \mathrm{g}$. Then, the supernatants were collected and kept at $-20^{\circ} \mathrm{C}$ for the measurement of liver function indices on a HITACHI 7060 automatic biochemical analyzer (Hitachi 7060, Hitachi Ltd., Tokyo, Japan). The other $5 \mathrm{~mL}$ of blood was collected under general anticoagulation (into blood collection tubes containing EDTA-K3), and the specimens were prepared for flow cytometry within $30 \mathrm{~min}$. To ensure maximum viability, stained cells were analyzed promptly (within 6 hours) for the detection of lymphocyte subsets.

\section{Establishment of the flow cytometry assay}

First, cell staining was conducted according to the instructions for operation, and the antibodies (against CD8, CD19, CD3, CD4, and NK cells) were added directly to the bottom of each test tube. Second, $100 \mu \mathrm{L}$ of evenly mixed whole blood was added directly to the bottom of the tube, and the tube was gently shaken. The flow tubes were protected from light and refrigerated at $4{ }^{\circ} \mathrm{C}$ for 30 minutes so that the various antibodies could fully combine with their corresponding receptors. Then, red blood cell lysis buffer was added and the tubes were gently shaken to lyse the red blood cells in the samples, and the samples were allowed to stand for 10 minutes, protected from light. Subsequently, $1.5 \mathrm{~mL}$ PBS was added to terminate red blood cell lysis, and the test tubes were placed in an oscillator for gentle shaking. Samples were separated by means of an automatic balance centrifuge at $350 \times \mathrm{g}$ for $5 \mathrm{~min}$. Then, the flow tubes were removed and the supernatants were quickly discarded so that only the bottom of the sediment was retained. Following the addition of another $2 \mathrm{~mL}$ PBS and gentle shaking, further centrifugation was conducted at $350 \times \mathrm{g}$ for $5 \mathrm{~min}$, and the supernatants were quickly discarded while the sediment was retained. Then, $0.5 \mathrm{~mL}$ cell suspension was added for cell suspension and surfacelabeled cell fixing, and the samples were placed at room temperature for $20 \mathrm{~min}$, followed by another centrifugation at $350 \times \mathrm{g}$ for $5 \mathrm{~min}$. After the supernatants were discarded, $2 \mathrm{~mL}$ film-breaking agent was added and a 10-min centrifugation was performed at $350 \mathrm{~g} / \mathrm{min}$. Furthermore, an intracellular labeled monoclonal antibody was added and mixed at $4{ }^{\circ} \mathrm{C}$ for 30 minutes. Then, the samples were washed twice with film-breaking agent and centrifuged, the supernatants were discarded, and another $0.5 \mathrm{~mL}$ PBS was added for cell suspension. Flow cytometry (BD Biosciences, Franklin Lakes, NJ, USA) was performed to detect labeled cells and analyze the results.

\section{Follow-up}

All included patients with prmary HCC were treated by surgical resection. Through telephone and outpatient follow-up, the follow-up period was lasted for one year until January 2015. Patients' survival and recurrence rates were recorded in details during the follow-up period. 


\section{Statistical methods}

For statistical analysis, SPSS 21.0 statistical software (SPSS Inc, Chicago, IL, USA) was used in this study. Measurement data are represented as $\overline{\mathrm{X}} \pm \mathrm{s}$ and were validated by a normality test. Comparisons of measurement data were performed with the $t$-test, and comparisons of categorical data were performed with the chi-square test. Survival estimates were calculated by the Kaplan-Meier analysis. $P<0.05$ was chosen as the significance level.

\section{ACKNOWLEDGMENTS AND FUNDING}

This project was supported by The National Natural Science Fund Project (81260319), and the National Science and Technology Major Project (2013ZX10002009-001-005). We would like to express our sincere appreciation to the reviewers for their helpful comments on this article.

\section{CONFLICTS OF INTEREST}

The authors have declared that no competing interests exist.

\section{REFERENCES}

1. El-Serag HB. Epidemiology of viral hepatitis and hepatocellular carcinoma. Gastroenterology. 2012; 142:1264-73 e1.

2. Altekruse SF, McGlynn KA, Reichman ME. Hepatocellular carcinoma incidence, mortality, and survival trends in the united states from 1975 to 2005. J ClinOncol. 2009; 27:1485-91.

3. Ferlay J, Shin HR, Bray F, Forman D, Mathers C, Parkin DM. Estimates of worldwide burden of cancer in 2008: Globocan 2008. Int J Cancer. 2010; 127:2893-917.

4. Cheng AL, Kang YK, Chen Z, Tsao CJ, Qin S, Kim JS, et al. Efficacy and safety of sorafenib in patients in the asiapacific region with advanced hepatocellular carcinoma: A phase iii randomised, double-blind, placebo-controlled trial. Lancet Oncol. 2009; 10:25-34.

5. Jemal A, Bray F, Center MM, Ferlay J, Ward E, Forman D. Global cancer statistics. CA Cancer J Clin. 2011; 61:69-90.

6. Chen QW, Cheng CS, Chen H, Ning ZY, Tang SF, Zhang X, et al. Effectiveness and complications of ultrasound guided fine needle aspiration for primary liver cancer in a chinese population with serum alpha-fetoprotein levels $</=200$ $\mathrm{ng} / \mathrm{ml}$ - a study based on 4,312 patients. PLoS One. 2014; 9:e101536.

7. Siegel R, Ward E, Brawley O, Jemal A. Cancer statistics, 2011: The impact of eliminating socioeconomic and racial disparities on premature cancer deaths. CA Cancer J Clin. $2011 ; 61: 212-36$
8. Parikh S, Hyman D. Hepatocellular cancer: A guide for the internist. Am J Med. 2007; 120:194-202.

9. Fouts TR, Bagley K, Prado IJ, Bobb KL, Schwartz JA, $\mathrm{Xu} \mathrm{R}$, et al. Balance of cellular and humoral immunity determines the level of protection by hiv vaccines in rhesus macaque models of hiv infection. ProcNatlAcadSci USA. 2015; 112:E992-9.

10. Uehata $\mathrm{T}$, Iwasaki $\mathrm{H}$, Vandenbon $\mathrm{A}$, Matsushita $\mathrm{K}$, Hernandez-Cuellar E, Kuniyoshi K, et al. Malt1-induced cleavage of regnase- 1 in cd4(+) helper t cells regulates immune activation. Cell. 2013; 153:1036-49.

11. Kozakiewicz L, Phuah J, Flynn J, Chan J. The role of b cells and humoral immunity in mycobacterium tuberculosis infection. AdvExp Med Biol. 2013; 783:225-50.

12. Whiteside TL. Immune modulation of $\mathrm{t}$-cell and $\mathrm{nk}$ (natural killer) cell activities by texs (tumour-derived exosomes). BiochemSoc Trans. 2013; 41:245-51.

13. Bindea G, Mlecnik B, Tosolini M, Kirilovsky A, Waldner M, Obenauf AC, et al. Spatiotemporal dynamics of intratumoral immune cells reveal the immune landscape in human cancer. Immunity. 2013; 39:782-95.

14. Pardoll DM. The blockade of immune checkpoints in cancer immunotherapy. Nat Rev Cancer. 2012; 12:252-64.

15. Yang J, Lu H, Guo R, Yan D, Ye P, Jin L, et al. Molecular profile of the $t$ cell receptor beta variable in peripheral blood lymphocytes from chronic asymptomatic hbv carriers. Pathog Dis. 2015; 73:1-9.

16. Yang J, Chen J, He J, Xie Y, Zhu Y, Cao H, et al. Profiling the repertoire of $\mathrm{t}$-cell receptor beta-chain variable genes in peripheral blood lymphocytes from subjects who have recovered from acute hepatitis b virus infection. Cell MolImmunol. 2014; 11:332-42.

17. Rankin L, Groom J, Mielke LA, Seillet C, Belz GT. Diversity, function, and transcriptional regulation of gut innate lymphocytes. Front Immunol. 2013; 4:22.

18. Vivier E, Ugolini S, Blaise D, Chabannon C, Brossay L. Targeting natural killer cells and natural killer t cells in cancer. Nat Rev Immunol. 2012; 12:239-52.

19. Sena LA, Li S, Jairaman A, Prakriya M, Ezponda T, Hildeman DA, et al. Mitochondria are required for antigenspecific $t$ cell activation through reactive oxygen species signaling. Immunity. 2013; 38:225-36.

20. Vazquez MI, Catalan-Dibene J, Zlotnik A. B cells responses and cytokine production are regulated by their immune microenvironment. Cytokine. 2015; 74:318-26.

21. Cerwenka A, Lanier LL. Natural killer cell memory in infection, inflammation and cancer. Nat Rev Immunol. 2016; 16:112-23.

22. Falkenberg KJ, Johnstone RW. Histone deacetylases and their inhibitors in cancer, neurological diseases and immune disorders. Nat Rev Drug Discov. 2014; 13:673-91.

23. Qin S, Ma S, Huang X, Lu D, Zhou Y, Jiang H. Th22 cells are associated with hepatocellular carcinoma development and progression. Chin J Cancer Res. 2014; 26:135-41. 
24. Makarova-Rusher OV, Medina-Echeverz J, Duffy AG, Greten TF. The yin and yang of evasion and immune activation in hcc. J Hepatol. 2015; 62:1420-9.

25. Boyman O, Sprent J. The role of interleukin-2 during homeostasis and activation of the immune system. Nat Rev Immunol. 2012; 12:180-90.

26. Sideras K, Kwekkeboom J. Cancer inflammation and inflammatory biomarkers: Can neutrophil, lymphocyte, and platelet counts represent the complexity of the immune system? TransplInt. 2014; 27:28-31.

27. Jerez A, Clemente MJ, Makishima $H$, Koskela $H$, Leblanc F, Peng Ng K, et al. Stat3 mutations unify the pathogenesis of chronic lymphoproliferative disorders of $\mathrm{nk}$ cells and t-cell large granular lymphocyte leukemia. Blood. 2012; 120:3048-57.

28. Rehermann B. Pathogenesis of chronic viral hepatitis: Differential roles of $t$ cells and nk cells. Nat Med. 2013; 19:859-68.

29. Pearce EL, Poffenberger MC, Chang CH, Jones RG. Fueling immunity: Insights into metabolism and lymphocyte function. Science. 2013; 342:1242454.

30. Srivastava S, Koch MA, Pepper M, Campbell DJ. Type i interferons directly inhibit regulatory t cells to allow optimal antiviral $t$ cell responses during acute $1 \mathrm{cmv}$ infection. J Exp Med. 2014; 211:961-74.

31. Fuchs S, Rensing-Ehl A, Speckmann C, Bengsch B, Schmitt-Graeff A, Bondzio I, et al. Antiviral and regulatory $\mathrm{t}$ cell immunity in a patient with stromal interaction molecule 1 deficiency. J Immunol. 2012; 188:1523-33.

32. Tsai CY, Allie SR, Zhang W, Usherwood EJ. Microrna mir155 affects antiviral effector and effector memory cd $8 \mathrm{t}$ cell differentiation. J Virol. 2013; 87:2348-51.

33. Bengsch B, Martin B, Thimme R. Restoration of hbvspecific $\mathrm{cd} 8+\mathrm{t}$ cell function by pd-1 blockade in inactive carrier patients is linked to t cell differentiation. J Hepatol. 2014; 61:1212-9.

34. Heiberg IL, Pallett LJ, Winther TN, Hogh B, Maini MK, Peppa D. Defective natural killer cell anti-viral capacity in paediatrichbv infection. ClinExpImmunol. 2015; 179:466-76.
35. Gao B, Radaeva S. Natural killer and natural killer t cells in liver fibrosis. BiochimBiophysActa. 2013; 1832:1061-9.

36. Yi HS, Lee YS, Byun JS, Seo W, Jeong JM, Park O, et al. Alcohol dehydrogenase iii exacerbates liver fibrosis by enhancing stellate cell activation and suppressing natural killer cells in mice. Hepatology. 2014; 60:1044-53.

37. Pradere JP, Kluwe J, De Minicis S, Jiao JJ, Gwak GY, Dapito DH, et al. Hepatic macrophages but not dendritic cells contribute to liver fibrosis by promoting the survival of activated hepatic stellate cells in mice. Hepatology. 2013; 58:1461-73.

38. Meng F, Wang K, Aoyama T, Grivennikov SI, Paik Y, Scholten D, et al. Interleukin-17 signaling in inflammatory, kupffer cells, and hepatic stellate cells exacerbates liver fibrosis in mice. Gastroenterology. 2012; 143:765-76 e1-3.

39. Tan Z, Qian X, Jiang R, Liu Q, Wang Y, Chen C, et al. Il17 a plays a critical role in the pathogenesis of liver fibrosis through hepatic stellate cell activation. J Immunol. 2013; 191:1835-44.

40. Lan T, Kisseleva T, Brenner DA. Deficiency of nox1 or nox4 prevents liver inflammation and fibrosis in mice through inhibition of hepatic stellate cell activation. PLoS One. 2015; 10:e0129743.

41. (Mailloux A W E-BPK. Collagen matrix deposition by hepatic stellate cells protects hepatocellular carcinoma from nk-mediated cytotoxicity[j].Cancer Research. 2014; 741670-.

42. Carloni V, Luong TV, Rombouts K. Hepatic stellate cells and extracellular matrix in hepatocellular carcinoma: More complicated than ever. Liver Int. 2014; 34:834-43.

43. Mitra A, Satelli A, Yan J, Xueqing X, Gagea M, Hunter CA, et al. Il-30 (i127p28) attenuates liver fibrosis through inducing nkg2d-rae1 interaction between nkt and activated hepatic stellate cells in mice. Hepatology. 2014; 60:2027-39. 